\title{
FEATURES
}

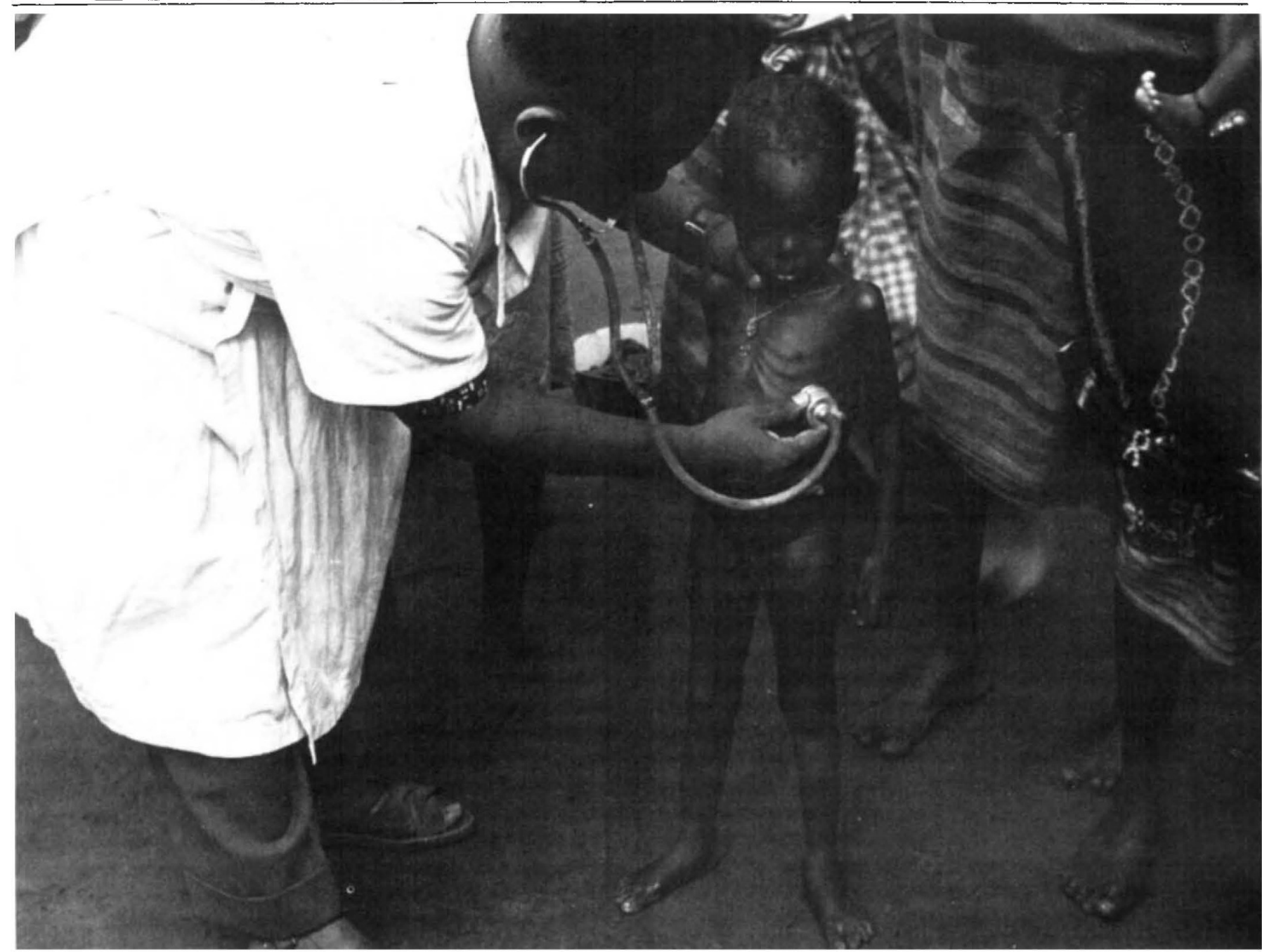

\section{Mahler's revolutionary study}

THE 1970s saw a debate on the role of science and technology in the economic and social development of the Third World. The failure of the development strategies propounded during the fifties and sixties had become clear. It has been repeatedly pointed out that the benefits of development programmes are not filtering through to the poor majority; western technology often helps to perpetuate rather than reduce economic and social injustice.

No international organisation has taken this to heart more than the World Health Organisation (WHO). This is ironical, because WHO is probably the best and most respected UN organisation in terms of technical competence, and this competence lies in western-style health technology.

But WHO has now set the goal of "health for all by the year 2000 ", and to achieve this, it is no longer advocating big hospitals, sophisticated medical technologies, and specialist medical professions. It is now talking about

\section{The UN General Assembly} recently approved the World Health Organisation's goal of health for all by the year 2000 . Here, the architect of WHO's new policy, Director General Halfdan Mahler explains his thinking to Anil Agarwal

concepts like primary health care which are based on such hitherto taboo ideas as community participation in health services, self-coping and self-care, appropriate technology for health, appropriate health cadres like 'barefoot doctors' and traditional medicine. The UN General Assembly endorsed WHO's new goal and its strategy of primary health care in November. All governments are now being asked to formulate by June strategies to achieve that goal.

The radical change in WHO's approach to health care has been described as the "Mahler revolution". Director General Halfdan Mahler has been a major force in the recognition that past health strategy has failed to bring any organised form of health care to more than half of the world's population living in rural areas and urban slums.

But the attempt at change has produced resistance. There is very little real political commitment, either in the developed world or amongst the elite of the developing world, to do much for the poor. WHO now finds itself saddled with idealistic international resolutions that few countries are really keen to implement back home, whether it is in terms of coming forward with the funds required to bring health care for all, or in terms of implementing those strategies and re-ordering domestic health priorities.

Lack of a real constituency is not the only problem. Even to prepare the intellectual framework for the change has meant antagonising such powerful actors 
in the existing health drama as the drug industry, the baby milk powder industry, the tobacco industry, and not least, the medical establishment. The latter exists within WHO itself. Convincing WHO's own secretariat of the new mission has not been an easy task; Mahler ruefully refers to his "electric chair".

Mahler was frank about how WHO is coping with the stresses and strains of this change.

"The constitution of WHO speaks of health as a human right; that physical, social and mental well-being should be at the highest possible level, so it was in the constitution of this organisation that it should have not only a narrow technical mission but also a social mission. This social mission was, however, neglected. In the 1950 s, we had the post-war hangover, the white man's guilt complex, that something ought to be done about the poor world. Isolated technical assistance programmes - lollipops, as I call them were developed. Everybody tried to do his missionary activity in the Third World, including me. WHO did some excellent technical work but in a number of rather narrow fields. Then came the reckoning in the 1960s that it is all very well to do a little bit of malaria control, some little work on some other communicable disease, but it doesn't get health down to the grass-roots. So in the 1960 s we had agonising questions such as: can WHO assume its real social mission?".

Mahler's strategy to bring the social mission to the fore has been simple: "I felt that the most important thing would be to invite the member-states to take their responsibility, whether they came from the North or the South. The big words, the collective decisions in the political organs of WHO, could no longer remain dead letters. This meant that the member-states had to ask WHO to be their bad conscience. We challenged them with the idea of health for all by the year 2000 . It was not shot down in flames. The view was expressed that this indeed ought to be our aspirational target. This then raised the question: what should be the tool in moving towards that goal? That led to the Alma Ata conference on primary health care (PHC) in 1978 and the charting of the primary health care approach.'”.

"There is now", according to Mahler, "in the governing bodies of WHO a realisation of what this movement towards health for all could become. Member states, however, often tend to forget individually what they have decided collectively".

The health debate has focused on two types of contradiction, says Mahler: "First, the conceptual contradiction. Previously we never dared to say that the end-product, health, should be attainable by everybody. We only spoke of services. We said we will try to get as big a coverage of services as possible.

"We have only a marginal degree of popular participation in health care. This is the fundamental contradiction: if health doesn't start with the individual, the home, the family, the working place, and the schools, then we will never get to the goal of health for all. Even if we take the example of the industrialised countries, self-care, self-responsibility, self-coping in the individual, family and community, represent $50-60 \%$ of all care. Unfortunately, health professionals are rarely willing to trust people to such an extent that they acquire power to make the decisions that have to do with their own health. I just don't believe that anything in the North, for instance, can truly be changed when it comes to overeating, overdrinking, abuse of drugs, overstress

GIf health doesn't start with the individual, the home, the family, the working place, and the schools, we will never get to the goal of health for all

and alienation, if we do not give power to the people to understand their own predicament, and then make conscious decisions about where they want to go."'.

In every country there is this fundamental contradiction between people and the medical consumer markets that they are provided with. "Of course", says Mahler, "the consumer markets in the developed countries are better because there you find, for instance, drugs all the time. That is because that is where the profits are. But if you go to a developing country, you find drugs available only for 3-4 months a year, which does not exactly generate confidence in the health services. Now by first looking at people's needs we know that we can no longer talk about putting drugs at random into the market. We must have a national policy whereby certain drugs are available all the time. Then we know we can get penicillin for the kid whenever he has pneumonia.".

The second major contradiction is that the health services like to deal with only the top $10 \%$ of the health pyramid. Medical education is such that it teaches the new professionals to love the highest technology and medical research and development is such that it likes to generate only the highest technology. Resource distribution in the medical sector is such that $80-90 \%$ of the resources go to meet $10-15 \%$ of the health problems."

In his speeches to the World Health Assembly, Mahler has repeatedly emphasised the need for a strong political commitment if these contradictions are to be resolved. They can be found everywhere in the world. "I have been in two developing countries in the last few months," explained Mahler. "In one of them, the head of state asked me for help in fighting the vector the mosquito. I replied:
'Mr President, indeed we have been trying to do that, but I do not think that we have vector control programmes that can prevent what is probably more important to you, that is, 100,000 or more kids dying from malaria every year. So by all means fight the vector, but let us not forget that it is somehow more important for people that 100,000 of their children will die this year from malaria.

"Now this is not a play on words. By focusing on the vector, we could easily bypass our political responsibility. (The first thing that ought to be done is to organise a system through community participation, if necessary, by which everyone who has or is likely to get malaria can easily get a tablet to prevent it or cure it).

"In the other country, the prime minister asked that WHO's entire budget for two years be used for buying a body scanner. For the same money that country could immunise its children against measles thus saving half a million children dying in the next ten years."

But what is actually happening in the health ministries of the Third World? "I am not speaking of any miracles happening, but I am convinced that there is a reappraisal going on in many developing countries. This is setting into motion within these countries strong confrontations." WHO's role, as Mahler sees it, "is to enable member-States who find it politically difficult to cope with these confrontations to make use of WHO's neutral platform to cope with them.

"Look, for instance, at drugs. It was very difficult to get a national drug policy going in the developing countries because of the resistance, whether it came from the medical specialists or the general physicians. WHO, for better or worse, has been trying to get the best talent around the world and they have been saying that a concept like essential drugs is perfectly valid. Essential drugs that can cope with $95 \%$ of the problems even in relatively sophisticated societies number around 200 . But for the Third World villager and urban slum-dweller great miracles can be achieved with 50 well-chosen drugs. It was WHO's neutral role as an arbiter that led to the realisation that there is nothing shameful in speaking about essential drugs. Now the onus is back on the governments. Can they now get their experts together and enforce this concept?"

In the confrontation over the marketing of baby milk powder, Mahler believes "WHO has played a unique role by providing a neutral platform. What we achieved was not a miracle, but when you compare it with the situation ten years ago, it was remarkable that industry, nongovernment organisations, and member states from developing and developed countries, could arrive at this kind of consensus. It was certainly a very 


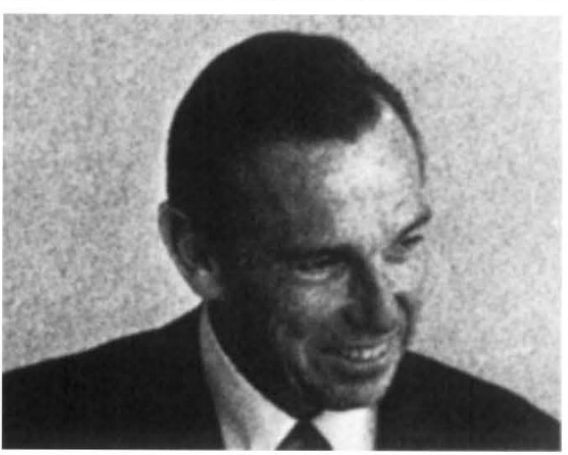

Halfdan Mahler:

$\mathbf{6}_{\text {Medical education is such that }}$ it teaches the new professionals to love the highest technology and medical research 9

unpleasant kind of confrontation. I was very concerned about WHO getting involved in it. But slowly we picked up the courage and hoped that it would not end in a disaster. And it didn't. Now memberstates will have a code of conduct for marketing of infant formulae. This will be a model which they can adapt to their conditions."

WHO has also had confrontations with the scientific community, which Mahler says "finds it very unpleasant when you speak about social relevance and social equity. But take these one million kids dying in Africa from tropical malaria. Somehow, it must be possible to mobilise enough social commitment among those scientists involved in health research to say that this cannot be tolerated when we have such fantastic scientific tools today. Well, scientists initially said we are prepared to do our little bit as long as it is marginal. Now through our diarrhoeal diseases, tropical diseases and human reproduction research programmes, we are dragging them. We have opened our doors to the scientists. I think the response has been very good and will be increasing in the future."

But is providing a neutral platform and creating a consensus enough in these confrontations? Is WHO happy with the speed with which the essential drugs programme is being implemented, for instance? "No, certainly not," says Mahler. "But then we have to ask ourselves whether WHO isn't becoming a little megalomaniac in this field of drugs. WHO now finds itself fighting the world at large. We are now moving straight into technology, production, patents, trademarks, the elements of a new international economic order in the widest possible sense. Is this WHO's role? I think we have set the scene, and other organisations like the UN Conference on Trade and Development, the UN Industrial Development Organisation, World Bank, etc, should now play the key role. If you look at the drugs scenario, despite its imperfections, there is already a lot of courage, in espousing the essential drugs idea, courage by a number of developing countries now developing national drug policies, and courage by member-states in the Pacific region, for instance, who have got together under WHO auspices to decide on collective purchasing so that they can negotiate with drug suppliers much more strongly than in the past.

"But still I am not happy with the speed of the essential drugs programme but that is because I am not happy with myself. I don't seem to have the necessary social or economic ability to accelerate the process. And, therefore, I want to involve UNIDO, UNCTAD, etc into whatever I can do, and the drug industry itself, by asking it what can be done. I can give you an example. It was rather startling. We had a conference and the industry spokesman said that the production of vaccines and sera is so competitive that they were losing interest in it. What conclusion can you draw from that? When you want health for all and want to prevent six million children from dying from tuberculosis. whooping cough, diphtheria, measles and polio every year, then you need to vaccinate 100-120 million children every year. In order to get that you need a vaccine price that is low. But when the price is low, you can't get the products. So my conclusion is that we can no longer treat these vital, essential components of people's health as normal commodities in the market place. They may have to be taken out of the market place and other ways found to produce these essential drugs. But all of this obviously generates tremendous contradictions."

But what about the contradictions inside the house? To what extent has the Mahler revolution filtered down within WHO itself? Mahler has several times told his staff that WHO should not be an academy of health sciences but a centre for managing health.

Mahler agrees that there is an internal contradiction. "It is difficult to take the plunge from doing things that you do well, to continue to do them well but with a very much sharper relationship with this overall target of health for all. The secretariat is asking, are we not throwing out the baby with the bath water? We had all these good technical things. Is the gap not too big between all these expectations of a social mission and our limited but well-done technical mission? This challenging target of health for all set by the member-states collectively is probably the only way of bringing the high priests on their toes - the high priests inside the secretariat and in the individual member-states."

Could not WHO's technical reputation suffer in the process? Could it not find that it has compromised its technical reputation as well as failed to achieve its social goal? Mahler believes that the danger is there, but it does not inhibit him.

"Take the case of smallpox eradication which was first decided on in 1957. The internal technicians in WHO - and don't forget I am one of them - claimed for ten years on technical grounds that the job could not be done. However, in 1968 we turned the argument around and said smallpox shall be eradicated and the political commitment shall be taken for granted. We worked backwards to see how our techniques and our management would allow this political commitment to manifest itself, and how our technologies could do the job. And we succeeded."

"Most people analysing the contemporary world will say, forget about health for all. They will tell you that you will soon have a nuclear war in several of the developing countries. If you look at the world without a feeling for this imperative, historical necessity to change, then obviously you will generate a climate of gloom, and then be discouraged by it. Inside WHO, we could have gone on with basic health services, some tuberculosis, some malaria work. But now we have forced ourselves politically into interfacing with the collective aspirations of our memberstates.

"I do not think that there is one person who can say that this change requires less of him technically. I think it requires infinitely more scientific imagination, in order to lift our technological thinking out of our cocoons in such a way that it relates more meaningfully to this broader social perspective. But I do not believe that in the process any of the conventional technical activities will be lost. In fact, the large majority will have become infinitely better within the next 5-10 years and more relevant to our social targets. In recent years, we have been generating the various research programmes, the expanded programme for immunisation, and planning for clean drinking water and sanitation, with the target of 'clean water and sanitation for all by 1990'. All these programmes have highly explicit objectives. These objectives are key components of primary health care. The programmes are helping people somehow to identify with the components of the overall strategy. So now you have within WHO a progressive improvement, from a kind of technocratic alienation to begin with, to an identification with the major programmes that will be filling out the various major gaps in primary health care."

WHO must become more responsive to the realities of the world, he says. "I have been asking member-states: do you really think that a technocracy like WHO should continue to exist? Either you believe that you can make WHO big enough to assume this brokerage role at the global, regional and country levels, or you don't. If you do, then we have to make a lot of agonising changes, and there will be no peace. But if and when the member-states realise that WHO cannot assume that larger mission, they should have the courage to say that we 
couldn't make the organisation swing around to what we all believe should be done, so let's get rid of it. Let us not keep the system for some spurious political motive."

But Mahler is optimistic on several counts: "I think that we have to a large extent successfully called the North-South bluff in health. And having called it, it is beginning to hurt. I know many politicians in the Third World are very uncomfortable with the present situation in which the elite is eating up $80-90 \%$ of the resources. There is a genuine debate on health in the industrialised countries too, though to a lesser extent."

Given the "hysterical conservatism" that is rampant in the developed countries, Mahler is still not sure to what extent they are prepared to help the developing countries achieve the goal. But he argues the South "now has a much better chance of moving towards self-reliance in health. Now it can challenge the North by saying that to achieve our collective goal of health for all which we all have collectively decided, we will do $95-97 \%$ of the job ourselves. Will you not let us have that $2-3 \%$ of support that is essential for us to make the best of our $95-97 \%$ ?

And why should the developed world help? Because in the process it would only help itself. "Take the case of smallpox eradication. Ironically, it is the rich world that is making, according to a moderate estimate, a profit of about a billion dollars a year - savings in vaccine production, in treatment of complications, in surveillance mechanisms, in the tremendous waste of time involved in having to make vaccination compulsory. Now I should have thought it moderately reasonable on my part to say that half of the profits should go back to the developing countries. They did it really for the sake of the developed countries. Take Africa. Their form of smallpox was not very serious. They could live with that. If you have a million children dying from malaria, it is not the most important thing to eradicate smallpox. But because of its committment to global solidarity, Africa had to eradicate smallpox. It just shows how interdependent the nations of the world are in health."

When developing countries undertake research into their own problems, even then the West benefits. "Take my own little experience in tuberculosis," says Mahler. "In the 1950s, when I went to work in India, we were exporting the classical European notion of TB sanatoria. India then had three million cases of TB and little money to diagnose, treat or immunise. Well, the government of India picked up the courage to do research itself, and indeed the consequence was that the chemotherapy research that came out of the Madras TB research centre became internationally the most important. The centre succeeded in standardising the procedure of diagnosis, and in developing the concept of

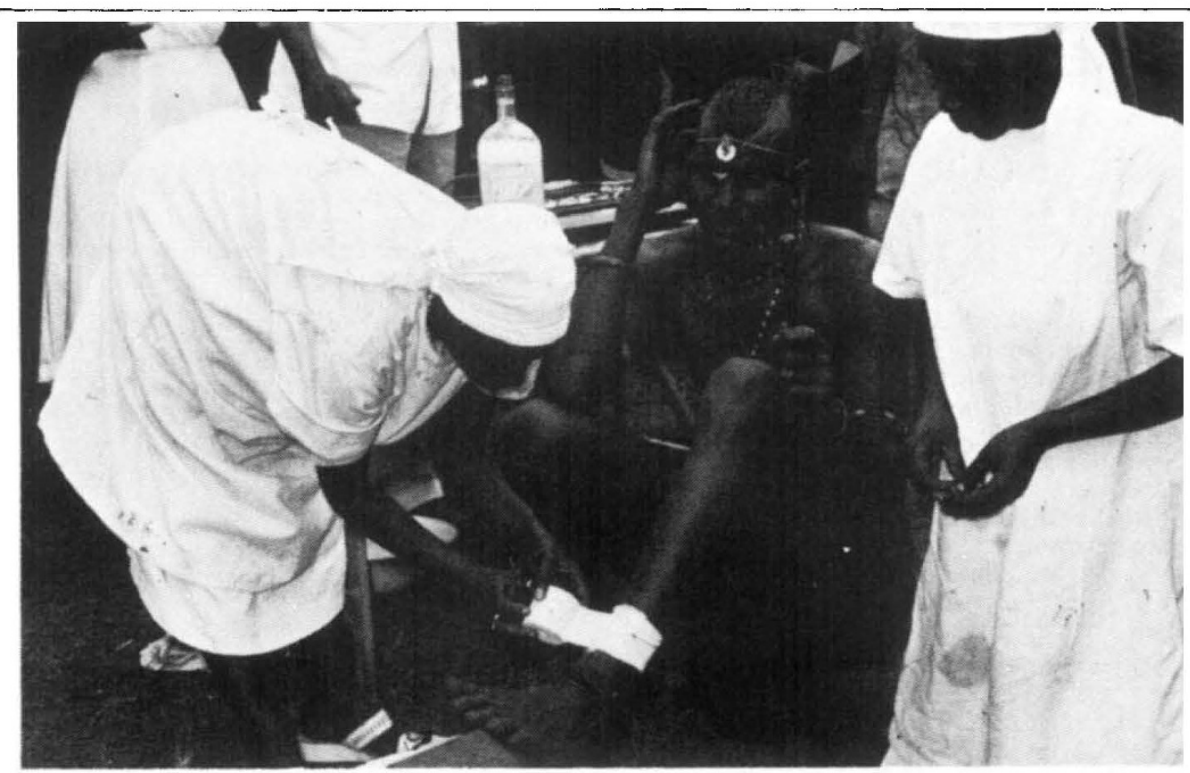

Medicine in two worlds: primary care in A frica, high technology in the North

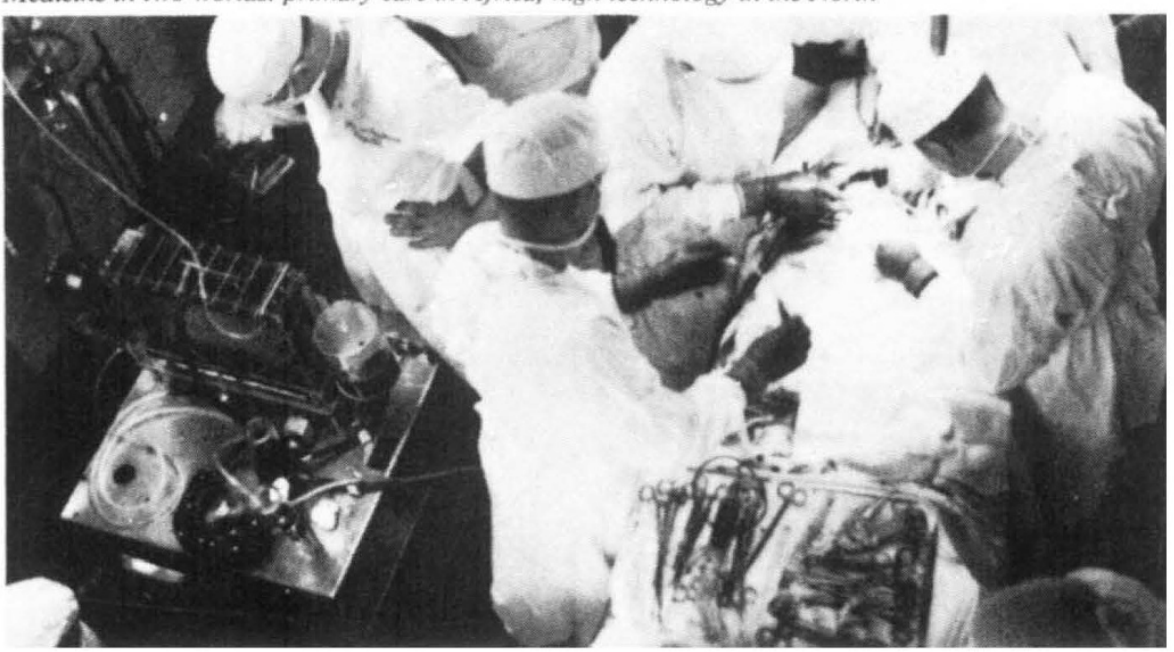

intermittent home-based treatment. All of this research was clearly geared to India's absolutely incredible problem, and these were studies that would never have been done anywhere else in the world.

"Yet, ironically, the great beneficiaries of all this research were the rich countries. Hundreds of millions of dollars have been gained in the developed countries by making use of the Indian research. A European country I recently visited has been able to avoid constructing 3,000 beds for TB treatment because they now have the WHO expert committee's recommendations based on research done in India that home-based treatment is adequate. This was the effect in just one developed country."

But probably what the developed countries will gain most is knowledge about how to handle their own health problems by emulating the approaches being developed in the Third World - a kind of reverse transfer of technology.

"Global standards of health and wellbeing are declining: life expectancy, after reaching a peak, is now again decreasing; cancer rates are rising; cardiovascular diseases are rampant; drugs, alcohol, cigarettes and traffic accidents nowadays kill more people than did all the epidemics together in earlier centuries; the aged are overwhelmed with diagnostic tools and abstruse technology, but their psychosocial and mental well-being is left largely unattended and uncared for.

"This uneasy feeling about today's medicine is widespread. As a consequence of the present high technological pitch of diagnostics and therapeutics, the very attempt to diagnose and treat one disease may produce another. As many as $20 \%$ of hospital admissions are reported to fall in this category in certain parts of the affluent world. Our world has become too accustomed to believe that with a little bit of resources and a little bit of knowledge any problem can be solved.

"I think that an appreciation of the South's real health problems will have a better chance to emerge once the North gets a feeling for the incredible irrationality that exists in its own health system. This will be an additional factor leading to the true global solidarity necessary to achieve health for all the world's peoples. If you look at our concepts about the transfer of science and technology, then I have no hesitation in saying that we really are out among the avant-garde." 